Biogeosciences, 10, 4897-4909, 2013

www.biogeosciences.net/10/4897/2013/

doi:10.5194/bg-10-4897-2013

(C) Author(s) 2013. CC Attribution 3.0 License.

\title{
Benthic buffers and boosters of ocean acidification on coral reefs
}

\author{
K. R. N. Anthony ${ }^{1,3}$, G. Diaz-Pulido ${ }^{2}$, N. Verlinden ${ }^{3}$, B. Tilbrook ${ }^{4}$, and A. J. Andersson ${ }^{5}$ \\ ${ }^{1}$ Australian Institute of Marine Science, Townsville, Qld 4810 Australia \\ ${ }^{2}$ Griffith School of Environment and Australian Rivers Institute - Coasts \& Estuaries, Nathan Campus, Griffith University, \\ Nathan, Queensland 4111, Australia \\ ${ }^{3}$ Biological Sciences, The University of Queensland, St Lucia, Q4072, Australia \\ ${ }^{4}$ Marine and Atmospheric Research, CSIRO, Hobart, Tasmania 7000, Australia \\ ${ }^{5}$ Scripps Institution of Oceanography, University of California San Diego, 9500 Gilman Drive, La Jolla, CA 92093-0202, \\ USA
}

Correspondence to: K. R. N. Anthony (k.anthony@aims.gov.au)

Received: 9 January 2013 - Published in Biogeosciences Discuss.: 1 February 2013

Revised: 9 June 2013 - Accepted: 15 June 201 - Published: 19 July 2013

\begin{abstract}
Ocean acidification is a threat to marine ecosystems globally. In shallow-water systems, however, ocean acidification can be masked by benthic carbon fluxes, depending on community composition, seawater residence time, and the magnitude and balance of net community production (NCP) and calcification (NCC). Here, we examine how six benthic groups from a coral reef environment on Heron Reef (Great Barrier Reef, Australia) contribute to changes in the seawater aragonite saturation state $\left(\Omega_{\mathrm{a}}\right)$. Results of flume studies using intact reef habitats $(1.2 \mathrm{~m}$ by $0.4 \mathrm{~m})$, showed a hierarchy of responses across groups, depending on $\mathrm{CO}_{2}$ level, time of day and water flow. At low $\mathrm{CO}_{2}$ (350-450 $\left.\mu \mathrm{atm}\right)$, macroalgae (Chnoospora implexa), turfs and sand elevated $\Omega_{\mathrm{a}}$ of the flume water by around 0.10 to $1.20 \mathrm{~h}^{-1}$ - normalised to contributions from $1 \mathrm{~m}^{2}$ of benthos to a $1 \mathrm{~m}$ deep water column. The rate of $\Omega_{\mathrm{a}}$ increase in these groups was doubled under acidification (560-700 $\mu \mathrm{atm})$ and high flow (35 compared to $8 \mathrm{~cm} \mathrm{~s}^{-1}$ ). In contrast, branching corals (Acropora aspera) increased $\Omega_{\mathrm{a}}$ by $0.25 \mathrm{~h}^{-1}$ at ambient $\mathrm{CO}_{2}(350-450 \mu \mathrm{atm})$ during the day, but reduced $\Omega_{\mathrm{a}}$ under acidification and high flow. Nighttime changes in $\Omega_{\mathrm{a}}$ by corals were highly negative $\left(0.6-0.8 \mathrm{~h}^{-1}\right)$ and exacerbated by acidification. Calcifying macroalgae (Halimeda spp.) raised $\Omega_{\mathrm{a}}$ by day (by around $0.13 \mathrm{~h}^{-1}$ ), but lowered $\Omega_{\mathrm{a}}$ by a similar or higher amount at night. Analyses of carbon flux contributions from benthic communities with four different compositions to the reef water carbon chemistry across Heron Reef flat and lagoon indicated that the net lowering of $\Omega_{\mathrm{a}}$ by coral-dominated ar-
\end{abstract}

eas can to some extent be countered by long water-residence times in neighbouring areas dominated by turfs, macroalgae and carbonate sand.

\section{Introduction}

Ocean acidification is the chemical consequence of the increasing carbon dioxide concentration in the atmosphere (Caldeira and Wickett, 2003; Sabine et al., 2004), and is a growing threat to marine calcifiers globally (Raven et al., 2005). Modelling studies, experimental evidence and reviews suggest that calcification rates of coral reef builders will decline significantly during this century (Kleypas et al., 1999; Langdon and Atkinson, 2005; Hoegh-Guldberg et al., 2007), shifting reefs from being net accreting to net dissolving communities (Andersson et al., 2009; Silverman et al., 2009). Ocean acidification projections, however, are mainly based on the exchange of carbon between atmosphere and openocean surface waters (Caldeira and Wickett, 2003; Gledhill et al., 2008) and therefore do not formally take account of the carbon exchange between seawater and benthic communities (Duarte et al., 2013). The carbon chemistry of tropical and subtropical, open-ocean surface seawater is largely driven by air-sea $\mathrm{CO}_{2}$ exchange, and increasing surface seawater $p \mathrm{CO}_{2}$ closely tracks the observed increase in atmospheric $\mathrm{CO}_{2}$ arising from anthropogenic activities (Bates and Peters, 2007; Orr, 2011). On short timescales (hours to decades), benthic carbon exchange has a small influence on the open 
ocean surface seawater. However, in shallow waters characteristic of tropical coral reefs and some coastal environmental settings, benthic carbon fluxes are superimposed on the anthropogenic carbon signal, and may in some situations mask variations in the carbon chemistry of the open ocean source water (Anthony et al., 2011; Santos et al., 2011).

Although a large body of evidence indicates that coral reefs are likely to become adversely affected by ocean acidification during this century (Kleypas et al., 1999; HoeghGuldberg et al., 2007; Silverman et al., 2009), spatial and temporal variation in physical reef settings (e.g. depth and flow) and benthic community composition is likely to interact with ocean acidification. For example, high rates of net photosynthesis of non-calcifying primary producers (macroalgae, benthic microalgae, seagrasses) can draw down $\mathrm{CO}_{2}$ significantly, potentially counteracting ocean acidification locally in shallow waters, and elevating seawater aragonite saturation state $\left(\Omega_{\mathrm{a}}\right)$ in downstream habitats. However, the net effect is dependent on the fate of the organic matter and whether it is stored as biomass, permanently buried in the sediments, exported or remineralized. As the rate of coral calcification is generally positively related to $\Omega_{\mathrm{a}}$ (e.g. Langdon and Atkinson, 2005; Schneider and Erez, 2006; Silverman et al., 2007), high rates of net photosynthesis in neighbouring upstream waters may enhance calcification downstream. Conversely, high rates of calcification in upstream habitats elevate $p \mathrm{CO}_{2}$ and lower $\Omega_{\mathrm{a}}$, potentially exacerbating ocean acidification and worsening the carbon chemical conditions for calcification in downstream habitats. These feedbacks between benthic carbon fluxes and seawater carbon chemistry have been explored for mixed reef communities (Suzuki, 1995; Bates et al., 2010), and recently for corals and macroalgae specifically (Anthony et al., 2011; Kleypas et al., 2011). To understand how different benthic habitats drive carbon chemistry changes on reefs, however, requires integration of carbon fluxes for a larger set of key benthic groups.

Benthic reef communities are composed of a broad suite of groups with different capacities for photosynthesis, metabolism, calcification and dissolution (Chisholm, 2000, 2003; Kleypas et al., 2011) and with varying responses to ocean acidification (Kroeker et al., 2010). The net direction and strength of these carbon flux processes will affect their contribution to carbon chemistry variation in reef waters. Here, we examine experimentally how the carbon fluxes (net photosynthesis and net calcification) of six common and abundant benthic groups in a shallow-water coral reef environment in the southern Great Barrier Reef (GBR) influence the $\Omega_{\mathrm{a}}$ of reef water under low $p \mathrm{CO}_{2}(350-450 \mu \mathrm{atm})$ and acidified (560-700 $\mu \mathrm{atm})$ conditions. To address this objective, we used a recirculating flume (550 L flow channel) to assay community carbon fluxes during the day and night, and for contrasting water flows ( 8 and $35 \mathrm{~cm} \mathrm{~s}^{-1}$ ) representing contrasting tidal states. This allowed interpretation of the feedbacks between natural changes in reef water carbon chemistry and benthic carbon fluxes, as well as potential impacts of ocean acidification on carbon flux processes in different reef habitats. We then used these community-level carbon flux data to address the question: to what extent will reefs with different benthic community compositions, particularly reefs with contrasting algal and coral abundances, and physical settings alleviate versus exacerbate natural carbon chemistry variation and ocean acidification?

\section{Methods}

\subsection{Modelling framework: integration of biological and physical processes}

The seawater saturation state with respect to calcium carbonate $\left(\mathrm{CaCO}_{3}\right)$ is defined as

$\Omega=\left[\mathrm{Ca}^{2+}\right]\left[\mathrm{CO}_{3}^{2-}\right] / K_{\mathrm{sp}}^{*}$,

where $K_{\mathrm{sp}}^{*}$ is the stoichiometric solubility product for a given $\mathrm{CaCO}_{3}$ mineral phase (e.g. aragonite or calcite). The solubility product is determined experimentally and corresponds to the product of calcium and carbonate ions at equilibrium, i.e. when the forward (precipitation) and backward (dissolution) reaction of $\mathrm{CaCO}_{3}$ are equal to one another at any given temperature, salinity and pressure. Because calcium concentration varies little in the ocean and is by a factor 30 to 50 greater than the concentration of the carbonate ion in surface seawater, $\Omega$ is mainly controlled by the abundance of this anion (Zeebe and Wolf-Gladrow, 2001). The $\left[\mathrm{CO}_{3}^{2-}\right]$, and hence $\Omega$, in seawater can be calculated from any given concentrations of total dissolved inorganic carbon $\left(C_{\mathrm{T}}\right)$ and total alkalinity $\left(A_{\mathrm{T}}\right)$, temperature, salinity and pressure (Dickson et al., 2007). Thus, changes in the aragonite saturation state $\left(\Omega_{\mathrm{a}}\right)$ under a given scenario under typical seawater saturation state conditions on coral reefs (where changes in $\Omega_{\mathrm{a}}$ are approximately linearly with the typical range of changes in $C_{\mathrm{T}}$ and $A_{\mathrm{T}}$; Fig. 1) can be expressed empirically:

$\frac{\mathrm{d} \Omega_{\mathrm{a}}}{\mathrm{d} t}=a \frac{\mathrm{d} A_{\mathrm{T}}}{\mathrm{d} t}+b \frac{\mathrm{d} C_{\mathrm{T}}}{\mathrm{d} t}$,

where $a$ and $b\left(\mathrm{~kg} \mathrm{umol}^{-1}\right)$ are regression coefficients that vary with any parameter (physical or chemical) that alters the relationship between $C_{\mathrm{T}}, A_{\mathrm{T}}$ and $\Omega_{\mathrm{a}}$. For example, rates of change in $A_{\mathrm{T}}$ and $C_{\mathrm{T}}$ are directly related to net rate of volume-specific net community production $\left(p_{\mathrm{nV}}, \mu \mathrm{molm} \mathrm{m}^{-3} \mathrm{~h}^{-1}\right)$, net community calcification $\left(g_{\mathrm{nV}}\right.$, $\left.\mu \mathrm{mol} \mathrm{m}{ }^{-3} \mathrm{~h}^{-1}\right)$ and air-sea exchange of $\mathrm{CO}_{2}\left(f_{\mathrm{nV}}\right)$ (Anthony et al., 2011):

$$
\frac{\mathrm{d} A_{\mathrm{T}}}{\mathrm{d} t}=-2 g_{\mathrm{nV}}
$$

$\frac{\mathrm{d} C_{\mathrm{T}}}{\mathrm{d} t}=-p_{\mathrm{nV}}-g_{\mathrm{nV}}+f_{\mathrm{nV}}$. 


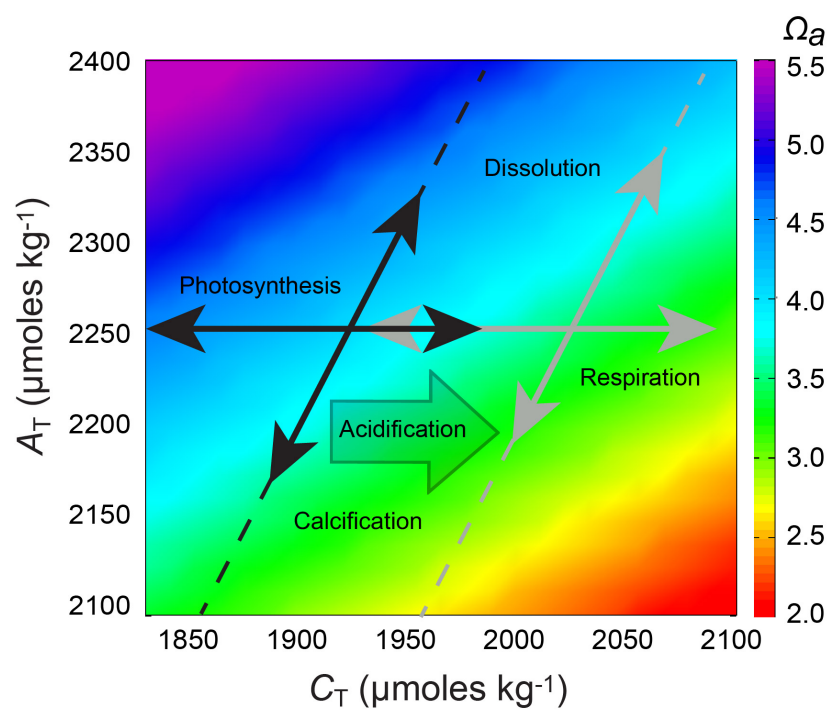

Fig. 1. Biogeochemical drivers of reef water carbon chemistry and effects of ocean acidification on aragonite saturation state $\left(\Omega_{\mathrm{a}}\right)$. Calcification and dissolution affect total alkalinity $\left(A_{\mathrm{T}}\right)$ as well as the concentration of dissolved inorganic carbon $\left(C_{\mathrm{T}}\right)$, whereas photosynthesis and respiration affect $C_{\mathrm{T}}$ only. $\Omega_{\mathrm{a}}$ changes linearly with $A_{\mathrm{T}}$ and $C_{\mathrm{T}}$ and can thus be expressed directly as a compound function of carbon fluxes (Eq. 5). Vectors indicate the directions and relative strengths of the benthic biological/biogeochemical processes under a present-day (solid) and acidified (dashed) scenario. Absolute vector lengths are hypothetical, but will vary with water depth, residence time, and the abundances and composition of primary producers and calcifiers. The projection was run for temperature $=27^{\circ} \mathrm{C}$ and salinity $=35$. Modified from Anthony et al. (2011).

To determine how benthic net community calcification and production affect $\Omega_{\mathrm{a}}$ via changes in $C_{\mathrm{T}}$ and $A_{\mathrm{T}}$, we consider carbon fluxes into a fixed, but advecting, uniformly mixed water mass; in other words, a water parcel of constant dimensions travelling over a homogeneous benthic community. The framework can be expanded to a spatially explicit model for complex community settings by taking into account horizontal and vertical advection and mixing (Falter et al., 2008). We convert volume-specific carbon fluxes to area-specific rates $\left(p_{n}\right.$ and $\left.g_{n}, \mu \mathrm{mol} \mathrm{m}{ }^{-2} \mathrm{~h}^{-1}\right)$ through division by water depth $(z, \mathrm{~m})$, under the assumption that the water column is equally mixed for different depths. Equations (2)-(4) can thus be combined to

$\frac{\mathrm{d} \Omega_{\mathrm{a}}}{\mathrm{d} t}=\frac{b\left(p_{n}-f_{n}\right)+g_{n}(b-2 a)}{z}$.

Values of the coefficients $a$ and $b$ represent the thermodynamic and compositional control of $K_{\mathrm{sp}}^{*}$ (Eq. 1) and were estimated using multiple regression analyses of Eq. (1) for a broad range of $C_{\mathrm{T}}$ and $A_{\mathrm{T}}$ values (1800-2100 and $2100-2400 \mu \mathrm{mol} \mathrm{kg}{ }^{-1}$, respectively, Fig. 1) and for temperature, salinity, pressure and nutrient conditions representative of shallow-water areas of tropical coral reefs $\left(20-30^{\circ} \mathrm{C}\right.$,
32-37 S, 1-2 bar, $<1 \mu \mathrm{M}$ phosphate). For each set of conditions, $\Omega_{\mathrm{a}}$ was calculated using $\mathrm{CO}_{2} \mathrm{SYS}$ (Lewis and Wallace, 1998). Here, $a$ ranged from 0.0105 to $0.0120 \mathrm{~m}^{2} \mathrm{mmol}^{-1}$ and $b$ ranged from 0.0090 to $0.0100 \mathrm{~m}^{2} \mathrm{mmol}^{-1}$. For the purpose of our analyses, we used the means of these ranges for $a$ and $b$, representing conditions on the study reef during the study period $\left(25^{\circ} \mathrm{C}, 35 \mathrm{~S}, 1 \mathrm{dbar}\right.$ and negligible nutrient levels).

\subsection{Study location and species}

This study was conducted at Heron Reef $\left(23^{\circ} 27^{\prime} \mathrm{S}\right.$, $151^{\circ} 54^{\prime} \mathrm{E}$ ) in the southern Great Barrier Reef (GBR, Australia, Fig. 2). This section of the GBR has a $3 \mathrm{~m}$ tidal range, with the reef crest and parts of the reef flat becoming air exposed at spring low tides, and submerged by $3-3.5 \mathrm{~m}$ of water during spring high tide. Heron Reef is a large lagoonal reef system with a well-defined fore reef, crest and extensive reef flat (Phinn et al., 2012). In the focus area, a diversity of Acropora species dominate the fore reef, crest and parts of the outer reef-flat zone. Pavements of crustose coralline algae (CCA, mainly Porolithon spp., including P. onkodes and Lithophyllum spp.) are also abundant on the wave-impacted front of the crest. Mixed zones of branching corals (large clones of Acropora aspera), fleshy and calcareous macroalgae (e.g. Halimeda) dominate the $50-100 \mathrm{~m}$ belt behind the crest (outer reef flat). Patches of sand and turfs (reef matrix with assemblages of cropped macroalgae and benthic microalgae) and scattered macroalgae increase in size and spatial dominance with distance from the crest and towards the lagoon or island. During the time of the study (October 2010-March 2011, Austral summer) the inner to midsections of the reef flat were characterised by a high abundance of fleshy macroalgae, predominantly Chnoospora implexa.

To determine the carbon flux contributions from major benthic groups to changes in the seawater carbon chemistry of the focus reef area, the following six groups were assayed in a detailed laboratory flume study: Corals (monospecific beds of Acropora aspera), crustose coralline algae (CCAs: mixture of different species of coralline red algae, including Porolithon onkodes, P. spp, Lithophyllum spp.), calcareous macroalgae (monospecific beds of Halimeda cuneata f. undulata), turf areas (assemblages of cropped and filamentous algae with scattered CCAs, fine sand and bare substrate), fleshy macroalgae (monospecific beds of Chnoospora implexa) and reef sand between patches of corals and mixed communities (Fig. 3). For each benthic group except CCAs, and for each replicate flume experiment, approximately $0.5 \mathrm{~m}^{2}$ of material was collected from the reef flat $(1.2 \mathrm{~m}$ by $0.4 \mathrm{~m}$ ); CCAs were collected from the reef crest. Care was taken to collect the material so that the in situ configuration of each habitat type (e.g. coral colony branch density) could be reproduced in the flume environment. The material was transported while submerged (or kept wet) in seawater to the aquarium facilities on Heron Island Research Station (HIRS). 


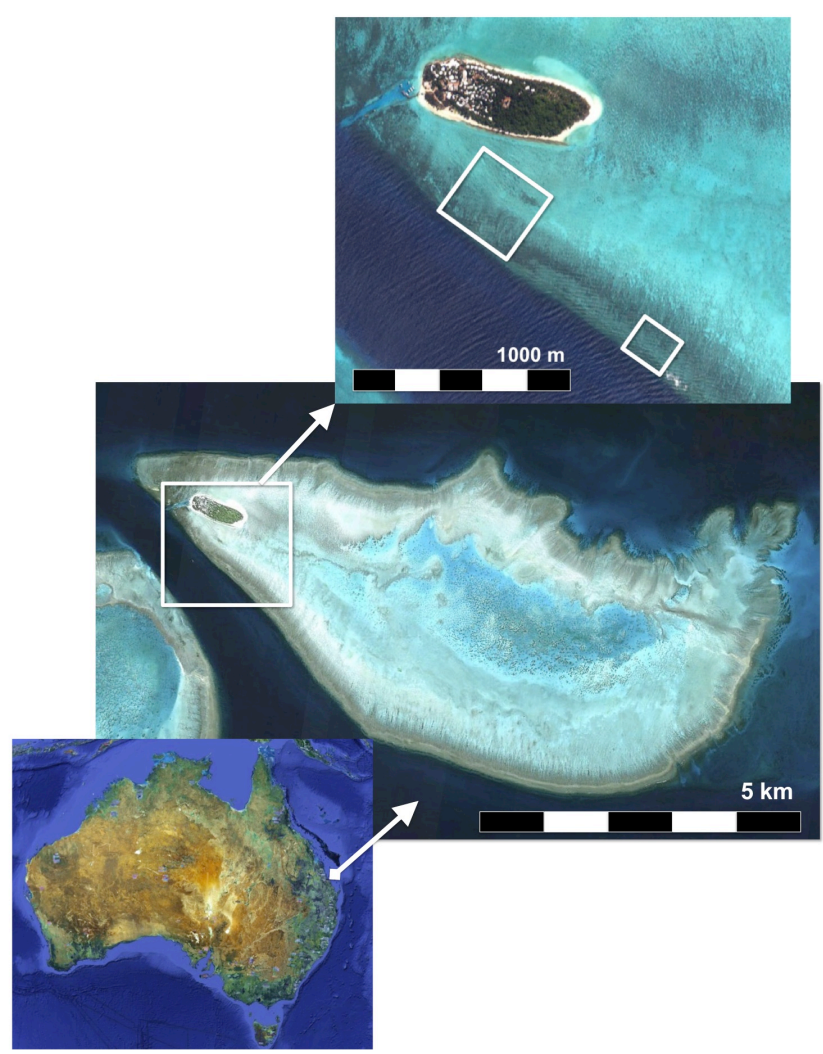

Fig. 2. Study areas on Heron Reef, Southern Great Barrier Reef, Australia. All benthic groups except crustose coralline algae (CCAs) were collected from across the $500 \mathrm{~m}$ reef flat within the large area (top insert). CCAs were collected from within the small area.

Only one habitat type was assayed per $48 \mathrm{~h}$ flume experiment to ensure that only fresh material was used.

Due to the large amount of reef material needed for each flume experiment $(1.2 \mathrm{~m}$ by $0.4 \mathrm{~m})$ for each benthic group (total of 2 tonnes of material), only 2-4 replicate experiments were run per group. However, because we used transplanted reef habitats as opposed to individual specimens, our carbon flux estimates for each flume experiment provided better representation of benthic carbon fluxes than a higher replication of smaller samples, as carbon fluxes over the larger intact areas used here absorbed the fine-scale within-habitat variation. Furthermore, as our analyses of how different benthic groups drive $\Omega_{\mathrm{a}}$ are not formally using the betweenexperiment variation, we focus here more of representation than replication.

\subsection{Flume studies: experimental design and environmental settings}

Flume experiments were designed to account for the effect of four variables on carbon fluxes: (1) habitat composition, (2) light/darkness, (3) flow environment, and (4) dissolved inorganic carbon chemistry (acidification). Firstly, effects of reef composition were tested by running duplicate or triplicate series of flume experiments for each of the six benthic groups, alternating between groups in time to avoid temporal dependence between replicate experiments. Secondly, benthic groups differ in their photosynthesis, metabolic rates and calcification responses over day-night cycles. Therefore, to obtain a full picture of their net effects on the seawater carbon chemistry requires an understanding of both day and night rates (Kleypas et al., 2011). Thirdly, the flow environment across Heron Reef varies diurnally due to tides, and episodically with wind and wave conditions. At the lowest tide, ponding water can be near stagnant over reef-flat habitats for up to $4 \mathrm{~h}$. At incoming high tide, currents over the reef crest and outer reef flat can vary from $<1 \mathrm{~cm} \mathrm{~s}^{-1}$ to $>30 \mathrm{~cm} \mathrm{~s}^{-1}$, depending on depth, winds and waves. Fourthly, the seawater carbon chemistry on and around Heron Reef shows strong diurnal and seasonal variation due to the net community production (NCP) and net ecosystem calcification (NEC) of the reef and neighbouring systems. For example, $p \mathrm{CO}_{2}$ of open surface waters SE of the study area (Wistari Channel) can range from 200 to $500 \mu$ atm between tidal cycles and seasons (www.pmel.noaa.gov/co2/story/Heron+Island). Also, in lagoonal or reef flat environments, the $p \mathrm{CO}_{2}$ range can extend to $150-700 \mu \mathrm{atm}$ and seawater aragonite saturation state $\left(\Omega_{\mathrm{a}}\right)$ can vary between 2 and 6 (Anthony et al., 2008).

\subsection{Experimental procedures and carbon flux experiments}

Each collected assemblage was reconstructed in the $1.2 \mathrm{~m}$ long by $0.4 \mathrm{~m}$ wide by $0.1 \mathrm{~m}$ deep working section of a laboratory flume (Fig. 3) and allowed to acclimate to laboratory conditions overnight. The flume is a $550 \mathrm{~L}$ recirculating Perspex raceway ( $2.4 \mathrm{~m}$ long by $1.2 \mathrm{~m}$ wide) with a $0.40 \mathrm{~m}$ wide by $0.25 \mathrm{~m}$ deep channel (Fig. 4). To mimic the roughness and structure of natural assemblages, Acropora, Chnoospora, Halimeda and turfs (rocks) protruded above the flume floor by $5-15 \mathrm{~cm}$ (Fig. 3a, c, d and f), whereas CCAs and sand were flush with the flume floor (Fig. $3 \mathrm{~b}$ and e). As the water in the flume was recirculating (repeatedly passing over the assemblages) it approximated Lagrangian water transects running along a path of reef with a monospecific assemblage. Flow velocity of the flume water was adjusted by an electrical outboard motor (WaterSnake $34 \mathrm{lb}$, Jarvis Marine, Dandenong, Australia) connected to a $12 \mathrm{~V}$ regulated power supply (Amtek, Meadowbank, Australia). Collimators were installed upstream of the $1.2 \mathrm{~m}$ long working section of the flume to reduce turbulence, which was verified by near-linear particle tracks in the midstream water above the assemblages along the entire working section. Light was supplied by two metal halide lamps $(2 \times 150 \mathrm{~W}$, AquaMedic, Germany $)$ producing down-welling irradiance of $\sim 1000 \mu \mathrm{mol} \mathrm{m}^{-2} \mathrm{~s}^{-1}$ at the level of the assemblages, measured by a Li-192s underwater light sensor (LiCor, Lincoln, NE, USA). 

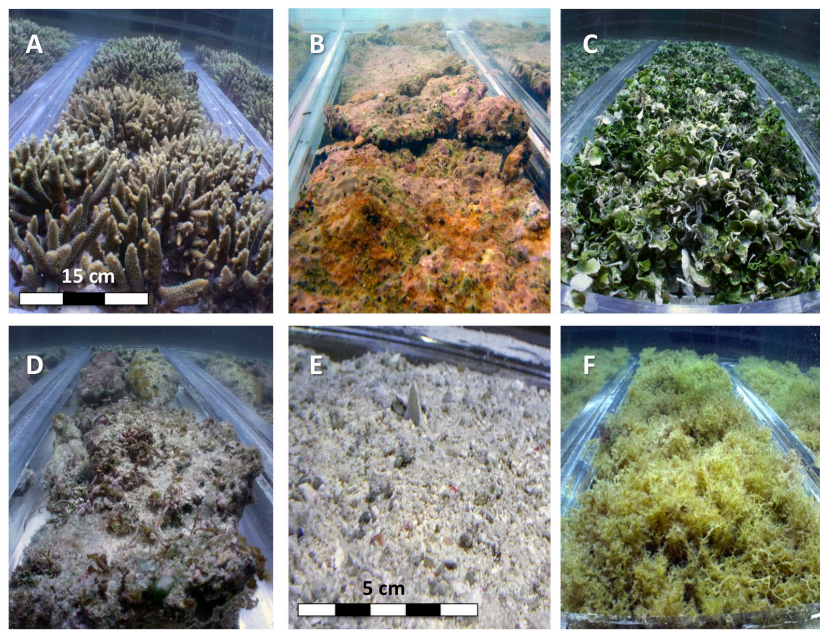

Fig. 3. Flume assemblages of six benthic groups from the Heron reef flat environment. (A) branching coral, Acropora aspera; (B) Crustose coralline algae (CCA) dominated by Porolithon onkodes; (C) calcifying macroalgae, Halimeda cuneata f. undulata; (D) turf assemblage consisting of a mixture of cropped algae, benthic microalgae and fine sand; (E) close-up of sand community dominated by a grain size of $0.5-2 \mathrm{~mm}$; and (F) fleshy macroalgae (Chnoospora implexa).

Flume experiments for each benthic group was replicated 2-4 times using newly collected assemblages for each experiment, with replicate experiments interspersed among those of other groups during a period of two months (October 2010-December 2010). Each experiment was run over $48 \mathrm{~h}$ : first day/night period in "ambient" $\left(350-450 \mu \mathrm{atm} \mathrm{CO}_{2}\right)$ seawater and second day/night period in "acidified" (560$700 \mu \mathrm{atm})$ seawater. The ambient and acidified treatments, as well as light and flow ranges, encompassed the range of physical and chemical variation characteristic of the Heron reef flat (Anthony et al., 2011; Santos et al., 2011). Before each series of flume runs, seawater was pumped from the reef flat at high tide at night and conditioned in a $2000 \mathrm{~L}$ aerated and temperature-controlled $\left(26-27{ }^{\circ} \mathrm{C}\right)$ storage tank. The $p \mathrm{CO}_{2}$ was adjusted by injecting balanced streams of $\mathrm{CO}_{2}$-free $(0$ $5 \mathrm{ppm})$ or $\mathrm{CO}_{2}$-enriched $(\sim 2000 \mathrm{ppm})$ air into the water overnight. $p \mathrm{CO}_{2}$ in both the storage tank and the flume water was measured using a submerged $\mathrm{CO}_{2}$-permeable, coiled silicone tube ( $4 \mathrm{~mm}$ diameter, $10 \mathrm{~m}$ long) connected in a closed loop to an infrared $\mathrm{CO}_{2}$ sensor and recording system (Vaisala GMP343/MI70) (Anthony et al., 2011). Ambient and acidified days were divided into $12 \mathrm{~h}$ light and $12 \mathrm{~h}$ dark periods. Within each period, $6 \mathrm{~h}$ sampling schedules were run at either low $\left(8 \mathrm{~cm} \mathrm{~s}^{-1}\right)$ or high $\left(35 \mathrm{~cm} \mathrm{~s}^{-1}\right)$ flow velocities to mimic flow variation across the reef flat due to tides. Between runs, around $80 \%$ of the flume water was replaced with new water from the storage tank (resetting $A_{\mathrm{T}}$ and $C_{\mathrm{T}}$ ). To determine net rates of calcification and photosynthesis, duplicate $500 \mathrm{~mL}$ water samples (in Schott glass bottles) were taken from the
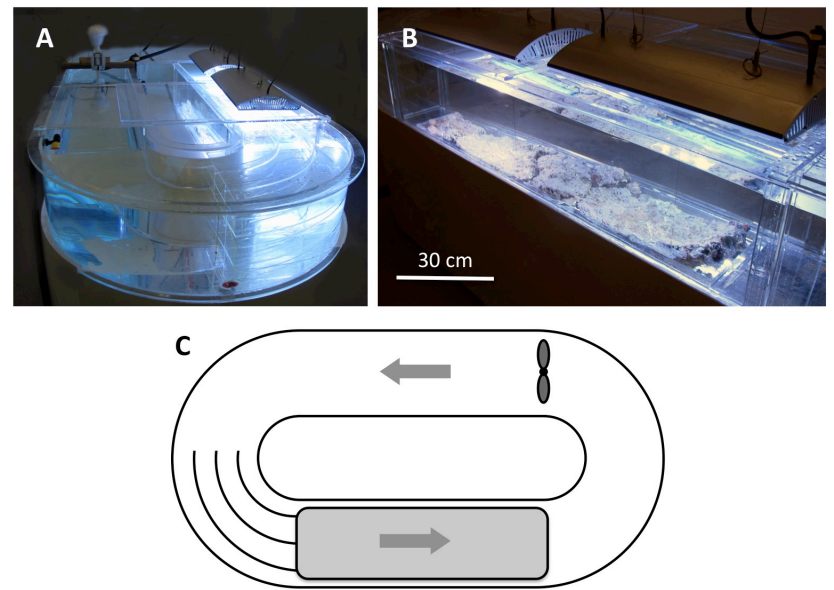

Fig. 4. Recirculating laboratory flume used for carbon flux studies of benthic reef flat communities. (A) and (B) end and side perspectives during run with a community of crustose coralline algae. (C) top-view diagram showing flow collimators (curved lines), flow direction (arrows) and position of propeller. The sunken $(0.1 \mathrm{~m})$ working section (grey area) measures $0.4 \mathrm{~m}$ by $1.2 \mathrm{~m}$.

flume water every $1-2 \mathrm{~h}$ during $6 \mathrm{~h}$ runs. Samples were poisoned immediately using $200 \mu \mathrm{L}$ saturated $\mathrm{HgCl}_{2}$ and stored for later $A_{\mathrm{T}}$ and $C_{\mathrm{T}}$ analyses.

To enable normalisation and comparison of net community calcification (NCC) and net community production (NCP) rates of experimental coral assemblages with those in situ, the ratio of 3-dimensional to planar surface area $\left(k_{\mathrm{r}}^{\prime}\right)$ of Acropora aspera in the flume was estimated after each series of light, $\mathrm{CO}_{2}$ and flow incubations. Here, lengths and diameters of all branches were measured and surface areas were modelled as cones and/or cylinders. For the replicate coral assemblages, $k_{\mathrm{r}}^{\prime}$ ranged from 9 to $11 \mathrm{~m}^{2} \mathrm{~m}^{-2}$. Similarly, to normalise carbon flux rates of macroalgae and $\mathrm{Hal}$ imeda communities, their dry weights (after rinsing in freshwater) were determined and expressed per $\mathrm{m}^{2}$ of seabed. The dry weights of Chnoospora implexa and Halimeda ranged between $55-70 \mathrm{~g} \mathrm{~m}^{-2}$ and $120-150 \mathrm{~g} \mathrm{~m}^{-2}$, respectively. As CCA, turf and sand communities were approximately planar, carbon fluxes for these assemblages were expected to be comparable to those in situ without further normalisation.

\subsection{Analyses}

Total alkalinity $\left(A_{\mathrm{T}}, \mu \mathrm{mol} \mathrm{kg}{ }^{-3}\right)$ was determined by Gran titration (Dickson et al., 2003) for duplicate subsamples weighed on an analytical scale $(\sim 100 \pm 0.001 \mathrm{~g})$. Subsamples were titrated in an open glass beaker with $0.05 \mathrm{~N} \mathrm{HCl}$ in the $\mathrm{pH}$ range $\sim 4$ to below 3 using a Mettler-Toledo (T50) system. $A_{\mathrm{T}}$ values were determined with a precision of \pm 2 $3 \mu \mathrm{mol} \mathrm{kg}{ }^{-1}$. Total dissolved carbon dioxide $\left(C_{\mathrm{T}}\right)$ was analysed at the CSIRO Marine Laboratories (Hobart, Australia) by acidifying the seawater to convert dissolved bicarbonate 
and carbonate ions to $\mathrm{CO}_{2}$, extracting the $\mathrm{CO}_{2}$ from the solution by bubbling with high purity nitrogen (>99.995\%), and trapping and quantifying the amount of $\mathrm{CO}_{2}$ using a UIC model 5011 coulometer (see detailed procedure in Johnson et al., 1993; Dickson et al., 2007). The precision of the measurements was $\pm 2 \mu \mathrm{mol} \mathrm{kg}{ }^{-1}$, based on the analyses of duplicate samples and certified reference material from Prof. A. Dickson's lab (Scripps Institution of Oceanography, USA).

Area-specific net rate of calcification $\left(g_{n}, \mathrm{mmol} \mathrm{m}^{-2} \mathrm{~h}^{-1}\right)$ was estimated based on the difference in total alkalinity ( $\Delta A_{\mathrm{T}}$, converted to $\mathrm{mmol} \mathrm{m}^{-3}$ ) of duplicate water samples collected before and after $2 \mathrm{~h}$ incubations, assuming $A_{\mathrm{T}}$ was solely affected by calcification and dissolution processes, and that $2 \mathrm{~mol}$ of $A_{\mathrm{T}}$ was consumed/produced for every mol $\mathrm{CaCO}_{3}$ precipitated/dissolved (Gattuso et al., 1995):

$g_{n}=\frac{\Delta A_{\mathrm{T}} V}{2 \Delta t S}$,

where $V$ is flume water volume $\left(0.55 \mathrm{~m}^{3}\right), \Delta t$ is time between sampling (h), and $S$ is the planar surface area of the benthic group $\left(0.5 \mathrm{~m}^{2}\right)$.

Net rate of photosynthesis $\left(p_{\mathrm{nV}}, \mathrm{mmol} \mathrm{m}^{-2} \mathrm{~h}^{-1}\right)$ was determined based on differences in total dissolved inorganic carbon $\left(\Delta C_{\mathrm{T}}, \mathrm{mmol} \mathrm{m}^{-3}\right)$ corrected for air-seawater exchange of $\mathrm{CO}_{2}\left(f_{n}\right)$ determined for empty flume runs (seawater only) at all light, $\mathrm{CO}_{2}$ and flow conditions and changes in $C_{\mathrm{T}}$ owing to net calcification estimated from $\Delta A_{\mathrm{T}}$ :

$p_{n}=\frac{\left(\Delta C_{\mathrm{T}}+f_{n}-\Delta A_{\mathrm{T}} / 2\right) V}{\Delta t S}$.

Air-sea $\mathrm{CO}_{2}$ exchange in the flume was calculated empirically for the different flow speeds and $p \mathrm{CO}_{2 \text { (aq) }}$ levels based on differences in $p \mathrm{CO}_{2}$ in water relative to air using the software $\mathrm{CO}_{2} \mathrm{Calc}$ (Robbins et al., 2010). For applications of Eq. (6) to projections in reef settings, $f_{n}$ was calculated using wind speed and gas exchange coefficients determined by Wanninkhof (1992).

For each benthic group and environmental condition, the contribution from the NCC and NCP to the benthic carbon fluxes and the resulting hourly rates of change in seawater aragonite saturation state of the overlying water column, $\Delta \Omega_{\mathrm{a}} / \Delta t$ was calculated based on $p_{n}, g_{n}$ and $f_{n}$. Here, $\Delta \Omega_{\mathrm{a}} / \Delta t$ was normalised to a $1 \mathrm{~m}^{2}$ planar surface area and a depth of $1 \mathrm{~m}$, the latter representing the average water depth across the Heron reef flat and across tidal states. Under assumptions of full mixing between reference points along the water path (Lagrangian transect), the contribution of benthic fluxes to $\Delta \Omega_{\mathrm{a}} / \Delta t$ will scale inversely with depth (Eq. 5).

Data on $g_{n}, p_{n}$ and $\Delta \Omega_{\mathrm{a}} / \Delta t$ as functions of light, flow and $\mathrm{CO}_{2}$ were not amenable to statistical testing as we used 2-4 repeated experiments with the objective of good representation (large benthic samples) rather than high replication. Therefore, carbon flux means of treatment combinations were compared based on the degree of overlap of error bars. To explore how combinations of light, flow velocity, $\mathrm{CO}_{2}$ regime and benthic groups drive hourly changes in $\Omega_{\mathrm{a}}$ over a reef flat area, carbon flux data from flume runs were used as input into Eq. (5) for four benthic reef compositions in shallow reef flat and lagoon environments. These compositions represented two general types of reef settings: (1) crest and outer reef flat environments and (2) back-reefs and lagoon. In turn, each type was represented by two scenarios: firstly, dominance of corals and crustose coralline algae (A); and secondly, dominance of macroalgae or turfs relative to corals. Compositions were based on extensive surveys of Heron reef environments (K. R. N. Anthony and G. Diaz-Pulido, pers. obs.) combined with analyses of hyperspectral remote sensing data (Phinn et al., 2012).

\section{Results}

\subsection{Effects of $\mathrm{CO}_{2}$ and flow on benthic day/night calcification}

Daytime calcification rates were highest for corals (maximum of $50 \mathrm{mmol} \mathrm{m}^{-2} \mathrm{~h}^{-1}$, grey columns in Fig. 5a) and lowest for turfs $\left(1-4 \mathrm{mmol} \mathrm{m}^{-2} \mathrm{~h}^{-1}\right.$, Fig. $\left.5 \mathrm{~d}\right)$ and sand $(-5$ to $1 \mathrm{mmol} \mathrm{m}{ }^{-2} \mathrm{~h}^{-1}$, Fig. 5e). Calcifying epibionts on the thalli of the non-calcifying macroalgae produced negligible NCC rates (Fig. 5f). Differences in flow velocity ( 8 vs. $35 \mathrm{~cm} \mathrm{~s}^{-1}$ ) did not affect daytime NCC under low $\mathrm{CO}_{2}$ in any group except sand (leftmost bars in Fig. 5a-e). Under acidification, however, low and high flow tended to reduce versus increased NCC, respectively, in corals and CCAs (Fig. 5a and b), but flow variation and acidification did not markedly affect NCC in Halimeda and turfs (Fig. 5c and d). Interestingly, high flow and acidification led to net daytime dissolution in the sand community (Fig. 5e).

Only corals showed markedly positive nighttime NCC rates, approximately $30 \%$ of daytime rates Fig. 5a). Conversely, nighttime NCC in CCAs, Halimeda, turfs and sand were mostly negative but varied with flow and $p \mathrm{CO}_{2}$ (Fig. 5b-e). Net nighttime calcification by CCAs decreased markedly (2-3 fold increase in net dissolution) in response to acidification (Fig. 5b). The nighttime NCC pattern for turfs was qualitatively similar to that of the CCAs whereas NCC pattern for Halimeda varied between marginally positive and negative (Fig. 5c). The sand community showed the strongest variation in $\mathrm{NCC}$ variation across treatment combinations (Fig. 5e). Interestingly, the pattern of nighttime NCC rates was largely similar to the daytime pattern. Specifically, NCC at low $\mathrm{CO}_{2}$ and low flow was not markedly different from zero, whereas high flow and acidification led to significant rates of dissolution. Other flow and $\mathrm{CO}_{2}$ combinations led to intermediate rates of dissolution (Fig. 5e).

Within-treatment variation in NCC between repeated experiments was generally low for all benthic groups, 


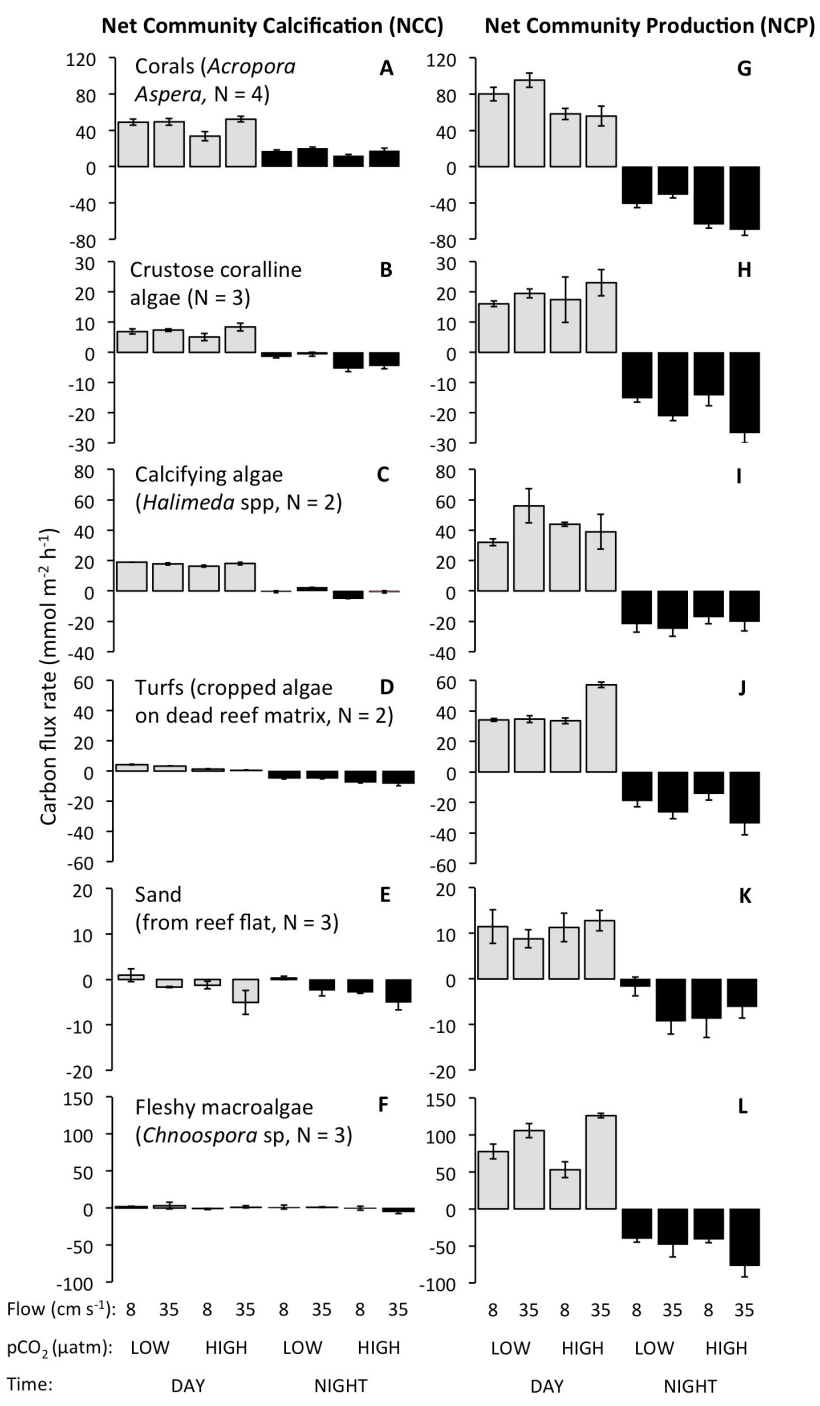

Fig. 5. Net rates of community calcification (left panels) and production (right panels) at high light (day, grey columns) and in darkness (night, black columns) under varying flow velocities ( 8 and $35 \mathrm{~cm} \mathrm{~s}^{-1}$ ) and $p \mathrm{CO}_{2}$ regimes (Low $=350-450 \mu \mathrm{atm}, \mathrm{High}=560$ $700 \mu \mathrm{atm})$. Data are means $\pm \mathrm{SE}$ of $N=2$ to 4 replicate communities. Note different scales on $y$ axes.

including Halimeda and turfs, which were only repeated once, demonstrating the high level of habitat representation of each experiment. Specifically, standard errors were generally less than $20 \%$ of the mean (Fig. 5).

\subsection{Effects of $\mathrm{CO}_{2}$ and flow on net rates of community production}

At low $\mathrm{CO}_{2}$, the net daytime rate of production (NCP) in corals (A. aspera) increased marginally under high flow, but declined by $20-30 \%$ under acidification at high and low flow (grey columns in Fig. 5g). Crustose coralline algae (CCAs) showed a similar marginal increase in day- time NCP with flow increase under low $\mathrm{CO}_{2}$, and a further marginal increase in the high $\mathrm{CO}_{2}$ and high flow combination (Fig. 5h). At ambient $\mathrm{CO}_{2}, \mathrm{NCP}$ in Halimeda was nearly doubled under high compared to low flow (Fig. 5i). Under acidification, however, NCP fell within the intermediate of this range. For turfs, daytime NCP increased around $75 \%$ in the acidification/high-flow combination compared to all other treatment combinations (Fig. $5 \mathrm{j}$ ). The sand community showed a weak and mixed NCP response to acidification and flow. Daytime NCP in the sand was potentially higher in the acidification/high-flow compared to the high-flow/low- $\mathrm{CO}_{2}$ combination (Fig. 5k). Lastly, NCP by fleshy macroalgae (Chnoospora implexa) increased around $25 \%$ with increased flow at low $\mathrm{CO}_{2}$ (Fig. 51). Under acidification, this difference increased to more than two-fold. Interestingly, the daytime macroalgal NCP declined around $30 \%$ in response to acidification at low flow, but was enhanced under acidification in high flow.

The negative nighttime NCP by A. aspera was nearly doubled under acidification, but independent of flow (black columns in Fig. 5g). In CCAs, high flow stimulated a further decrease in nighttime NCP, especially under acidification (Fig. 5h). In contrast to corals and CCAs, nighttime NCP in Halimeda was 20-30\% reduced under acidification, but was unaffected by variation in flow speed (Fig. 5i). The nighttime NCP pattern for turfs was qualitatively similar to that of the CCAs (Fig. 5j). High flow led to a marked drop in nighttime NCP for the sand community under low $\mathrm{CO}_{2}$ (Fig. 5k). This drop in NCP was maintained under acidification at low flow, but increased marginally under high flow. The pattern of nighttime NCP by the fleshy macroalgae was qualitatively similar to that of the turfs, except absolute NCP rates were more than 2 fold higher in the macroalgae (Fig. 51). Analogous to results for NCC, within-treatment variation in NCP was low, less than $30 \%$ of the mean for most treatment combinations and benthic groups.

\subsection{Contributions from benthic groups to changes in aragonite saturation state $\left(\Omega_{a}\right)$}

Net daytime carbon fluxes driven by corals (A. aspera) led to positive changes in the $\Omega_{\mathrm{a}}$ of the flume water at low $\mathrm{CO}_{2}$ (grey columns in Fig. 6a). Here, high flow led to a doubling of the positive $\Omega_{\mathrm{a}}$ change over corals (from $0.12 \pm 0.07$ to $0.26 \pm 0.08 \mathrm{~h}^{-1}$ ). Under acidification, however, a change from low to high flow shifted the daytime $\Omega_{\mathrm{a}}$ changes from positive to negative $\left(-0.15 \pm 0.10 \mathrm{~h}^{-1}\right)$ owing to increasing net community calcification. At night, corals lowered the flume water $\Omega_{\mathrm{a}}$ dramatically $\left(-0.55\right.$ to $\left.-0.86 \mathrm{~h}^{-1}\right)$, approximately 3-5 times more so than the positive changes during the day (black columns in Fig. 6a). Here, the negative nighttime changes in $\Omega_{\mathrm{a}}$ were $20-30 \%$ greater than under low $\mathrm{CO}_{2}$ mainly as a result of increasing dark respiration.

Contributions from crustose coralline algae (CCAs) to changes in $\Omega_{\mathrm{a}}$ were less than $20-30 \%$ of the changes 
observed for the corals (Fig. 6b, note different scales on $y$ axes). Also, in contrast to corals, daytime changes in $\Omega_{\mathrm{a}}$ over the CCA community did not vary significantly among $\mathrm{CO}_{2}$ levels and flow speeds, but showed large variation at night. Specifically, at ambient $\mathrm{CO}_{2}$, negative $\Omega_{\mathrm{a}}$ changes by CCAs at night were amplified under high flow by around $50 \%$ as a result of increasing dark respiration. Interestingly, acidification reduced the negative $\Omega_{\mathrm{a}}$ change at low flow by more than $50 \%$ (potentially due to net dissolution), but the combination of acidification and high flow did not alter the $\Omega_{\mathrm{a}}$ change compared to the ambient $\mathrm{CO}_{2}$ /high-flow combination (Fig. 6b).

The daytime pattern of $\Omega_{\mathrm{a}}$ changes caused by the $\mathrm{Hal}$ imeda communities largely reflected the pattern of net community production in this group (Figs. 5c and 6c). At low $\mathrm{CO}_{2}$, high flow increased the $\Omega_{\mathrm{a}}$ change five-fold (but with large uncertainty due to low community replication). Under acidification, the daytime change in $\Omega_{\mathrm{a}}$ was increased four-fold within the low-flow treatment relative to the low-flow/low- $\mathrm{CO}_{2}$ conditions. The uncertainly around $\Omega_{\mathrm{a}}$ changes in the high flow treatments was too large to allow comparison with other treatment combinations. At night, negative changes in $\Omega_{\mathrm{a}}$ were decreased by approximately $50 \%$ under acidification (Fig. 6c), in part due to the increased, albeit low, net dissolution at high $\mathrm{CO}_{2}$ and decreasing dark respiration (Fig. 5c). Overall, positive changes in $\Omega_{\mathrm{a}}$ by Halimeda during the day were approximately balanced by negative changes during the night.

Turf areas elevated seawater $\Omega_{\mathrm{a}}$ by more than 0.2 during the day, and almost twice so compared to negative changes in $\Omega_{\mathrm{a}}$ at night (Fig. 6d). Interestingly, the acidification/highflow combination elevated $\Omega_{\mathrm{a}}$ almost twice that of the other treatment combinations $\left(0.52 \pm 0.02 \mathrm{~h}^{-1}\right)$. The nighttime pattern in $\Omega_{\mathrm{a}}$ changes over turfs followed that of CCA and Halimeda, except that $\Omega_{\mathrm{a}}$ changes over turfs were smaller for the acidification/low-flow treatment

The daytime pattern in $\Omega_{\mathrm{a}}$ changes over the sand community was comparable to that of turfs, but with $\Omega_{\mathrm{a}}$ changes being around $50 \%$ lower and exhibiting more within-treatment variation (Fig. 6e). Daytime changes in $\Omega_{\mathrm{a}}$ in the sand incubations were also more than twice those at nighttime. Analogous to turfs, the positive $\Omega_{\mathrm{a}}$ change by turfs in the acidification/high-flow combination was around $50 \%$ greater than at ambient $\mathrm{CO}_{2}$ for both flows. At night, carbon fluxes in the sand community led to a marginally decreased $\Omega_{\mathrm{a}}$ at ambient $\mathrm{CO}_{2}$, but this pattern was reversed under acidification/high flow treatment (Fig. 6e).

In contrast to the pattern for corals and to some extent CCAs, hourly changes in $\Omega_{\mathrm{a}}$ driven by macroalgae (Chnoospora implexa) were high $\left(0.5-1.1 \mathrm{~h}^{-1}\right)$ for all $\mathrm{CO}_{2}$ and flow combinations during the day (Fig. 6f). Here, $\mathrm{CO}_{2}$ and flow showed interaction: positive $\Omega_{\mathrm{a}}$ changes were exacerbated by flow, and the flow effect was further enhanced under acidification. Interestingly, acidification led to reduced change in $\Omega_{\mathrm{a}}$ at low flow. At night, the acidification/high-

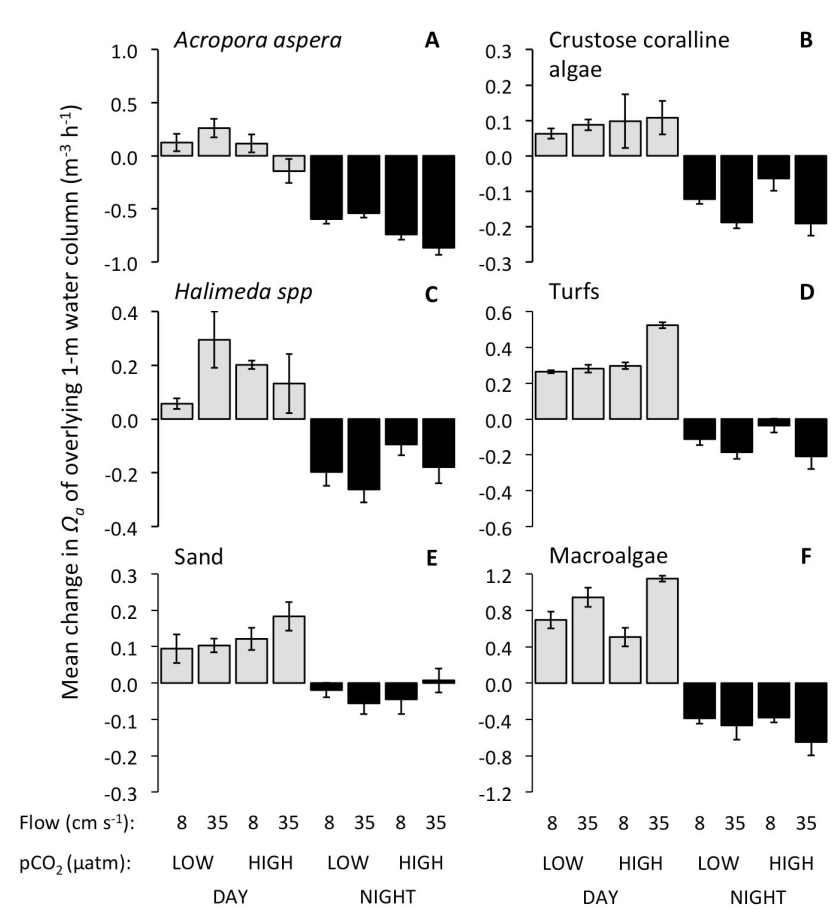

Fig. 6. Estimated hourly changes in seawater aragonite saturation state $\left(\Delta \Omega_{\mathrm{a}} / \Delta t\right)$ for benthic groups in a $1 \mathrm{~m}$ deep reef flat area based on Eq. (5) and carbon flux rates in Fig. 1. Error bars are standard errors of the mean determined based on Monte Carlo analyses of data in Fig. 5 (see methods). Note different scales on $y$ axes.

flow combination enhanced negative $\Omega_{\mathrm{a}}$ changes by $20-$ $30 \%$. Similar to the turfs and sand communities, carbon fluxes by $C$. implexa led for most $\mathrm{CO}_{2} /$ flow combinations to significantly positive net changes in $\Omega_{\mathrm{a}}$ over the day/night cycle.

\subsection{Relative contributions from carbon flux processes to $\boldsymbol{\Omega}_{\mathrm{a}}$ patterns}

The six benthic groups varied with respect to carbon flux contributions to $\Omega_{\mathrm{a}}$ changes from photosynthesis, calcification, respiration and dissolution. In corals, contributions were strongly, and almost equally, driven by photosynthesis and calcification during the day and respiration and calcification by night (Fig. 7a). In CCAs, daytime changes in $\Omega_{\mathrm{a}}$ were driven slightly more by net community production than calcification (Fig. 7b). At night, $\Omega_{\mathrm{a}}$ changes by CCA were driven by respiration and to an increasing degree by dissolution under acidification. The partitioning of flux contributions from Halimeda followed a similar pattern to that of CCAs except with less dissolution and a larger contribution from net community production under acidification (Fig. 7c). The pattern of flux contributions to $\Omega_{\mathrm{a}}$ changes for turfs and macroalgae were largely similar in that they were near parallel with the p-r axis under ambient $\mathrm{CO}_{2}$ (Fig. $7 \mathrm{~d}$ and f). Under acidification, turfs in particular showed a larger contribution from 


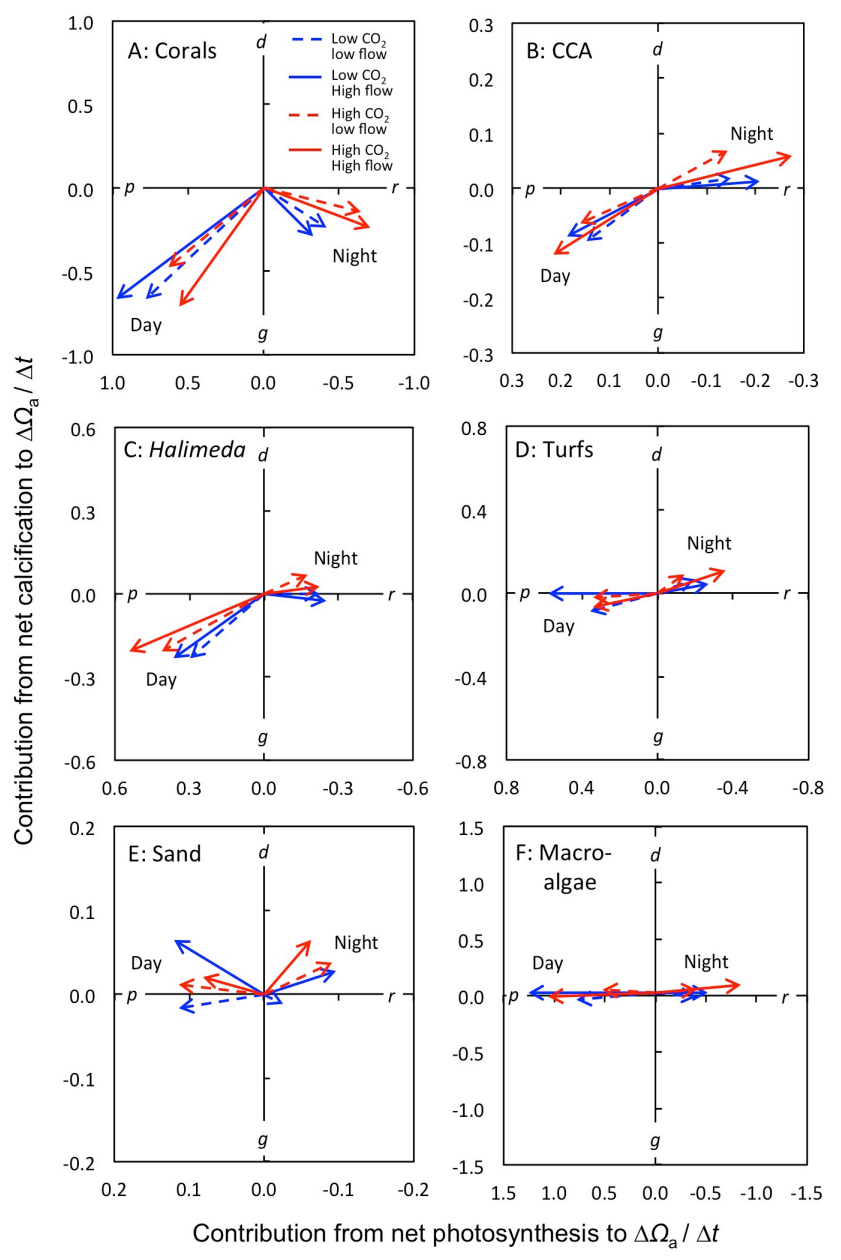

Fig. 7. Partitioning of contributions from net photosynthesis ( $x$ axis) and net calcification ( $y$ axis) to changes in aragonite saturation state ( $\Delta \Omega_{\mathrm{a}} / \Delta t$ for $1 \mathrm{~m}$ water depth) depicted in Fig. 6 . The contribution from net photosynthesis was calculated as $b p_{n}$ (corrected for air-sea $\mathrm{CO}_{2}$ exchange) and the contribution from net calcification was calculated as $g_{n}(b-2 a)$, forming the two terms in Eq. (5). The lengths of arrows are proportional to their contribution to $\Delta \Omega_{\mathrm{a}} / \Delta t$. Note different scales on both axes and the reversed scale of the $x$ axis. The symbols $p, r, g$ and $d$ denote the direction towards photosynthesis, respiration, calcification and calcium carbonate dissolution, consistent with $C_{\mathrm{T}}$ and $A_{\mathrm{T}}$ axes in Fig. 1.

dissolution. The flux contribution pattern for sand was nearly the opposite of that of corals (Fig. 7e). Here, dissolution was a dominant driver especially under high flow.

\subsection{Predicted changes in $\Omega_{\mathrm{a}}$ by different benthic communities}

To estimate how different benthic habitats contribute to carbon chemistry changes across shallow-water reef environments, we used four community compositions representing those found in two major zones: crest/outer reef flat and back-reef/lagoon. For crest/outer reef flat we compared the observed changes in $\Omega_{\mathrm{a}}$ driven by coral versus algaldominated habitats. This community variation reflects differences between parts of the reef crest and reef flat, seasonal variation in algal abundance, and to some extent variation in herbivory on macroalgae. Also, the contrasts in community composition within zones used here can represent a shift from coral to algal dominance expected temporarily under environmental stress including cyclones and bleaching events. For the back-reef/lagoon environment we compared a sand/turf-dominated habitat with varying abundance of macroalgae. Again, these scenarios represent spatial and seasonal variation as well as community shifts caused by disturbances. As most shallow-water habitats across Heron Reef experience varying water flows over the day due to tides and wind (Gourlay and Colleter, 2005), we combined flux data for low and high flow rates and only produced community estimates of $\Omega_{\mathrm{a}}$ changes for day versus night and for ambient versus high $\mathrm{CO}_{2}$.

Diurnal net carbon fluxes by the coral-dominated $(60 \%)$ crest community led to marginally negative $\left(-0.11 \pm 0.09 \mathrm{~h}^{-1}\right)$ average changes in $\Omega_{\mathrm{a}}$ under ambient $\mathrm{CO}_{2}$ but significantly negative average $\Omega_{\mathrm{a}}$ changes under acidification $\left(-0.23 \pm 0.14 \mathrm{hh}^{-1}\right.$, Table $\left.1 \mathrm{Bi}\right)$. At ambient $\mathrm{CO}_{2}$, the negative nighttime value of $\Delta \Omega_{\mathrm{a}} / \Delta t$ driven by the coral dominated community $\left(-0.43 \mathrm{~h}^{-1}\right)$ was almost twice the positive value during the day $\left(0.21 \mathrm{~h}^{-1}\right)$. Under acidification, this difference increased to almost 5-fold $\left(-0.57\right.$ vs. $\left.0.13 \mathrm{~h}^{-1}\right)$. This was partly due to the drop in $\Delta \Omega_{\mathrm{a}} / \Delta t$ under acidification, which was driven principally by reduced NCP.

In contrast, the daily average $\Delta \Omega_{\mathrm{a}} / \Delta t$ value over the macroalgae/turfs/sand-community (representing a coral and CCA degraded habitat) in the back-reef/lagoon environment was marginally positive $\left(\sim 0.12 \pm 0.09 \mathrm{~h}^{-1}\right)$ under both ambient and high $\mathrm{CO}_{2}$ regimes (Table 1Biv). Here, positive daytime changes in $\Omega_{\mathrm{a}}$ were approximately twice the negative nighttime changes $\left(0.47\right.$ vs. $-0.21 \mathrm{~h}^{-1}$ and 0.45 vs. $-0.22 \mathrm{~h}^{-1}$, respectively). This community type (iv) elevated $\Omega_{\mathrm{a}}$ twice as much as the coral community (i) during the day at ambient $\mathrm{CO}_{2}$ and four-fold under acidification. At night, the macroalgae/turf/sand community lowered $\Omega_{\mathrm{a}}$ by only half that of the coral community.

In the mixed turf/macroalgae (ii) and sand/macroalgae (iii) back-reef and lagoon environments, benthic carbon fluxes driving positive changes in $\Omega_{\mathrm{a}}$ during the day were balanced almost completely by negative changes at night (Table $1 \mathrm{Bii}$ and iii). The large negative nighttime values of $\Delta \Omega_{\mathrm{a}} / \Delta t$ for the turf/macroalgae community (ii) were due to a significant amount of coral $(15 \%)$ and fleshy macroalgae $(30 \%)$, both having high rates of dark respiration (Fig. 5). Similar to the macroalgae/sand/turf community in the lagoon environment (iv), but in contrast to corals (i), acidification did not significantly change the extent to which benthic carbon fluxes affected $\Omega_{\mathrm{a}}$. 
Table 1. Four scenarios for (A) benthic reef community compositions across the shallow-water environments of Heron Reef flat and lagoon, and their (B) predicted impacts on hourly changes in the aragonite saturation state $\left(\Delta \Omega_{\mathrm{a}} / \Delta t \mathrm{~h}^{-1}\right)$ of a $1 \mathrm{~m}$ deep water column under ambient (350-450 $\mu \mathrm{atm})$ and high (560-700 $\mu \mathrm{atm}) \mathrm{CO}_{2}$. Effects of flow are omitted so data encompass daily flow variation. Projections assume full vertical mixing and advection only. Estimates of $\Delta \Omega_{\mathrm{a}} / \Delta t$ are here the sum of hourly day and night contributions (assuming $12 \mathrm{~h}$ day : $12 \mathrm{~h}$ night) from the benthic groups based on data in Fig. 5. Means of day and night contributions are given on bold. Standard errors (in brackets) are calculated using Monte Carlo analyses - see methods.

\begin{tabular}{|c|c|c|c|c|c|}
\hline & \multirow[b]{2}{*}{ Scenarios: } & \multicolumn{2}{|c|}{ Crest/outer reef flat } & \multicolumn{2}{|c|}{ Back reef/lagoon } \\
\hline & & $\begin{array}{r}\text { (i) Corals/ } \\
\text { CCAs/ } \\
\text { turfs }\end{array}$ & $\begin{array}{r}\text { (ii) Turfs/ } \\
\text { macroalgae/ } \\
\text { corals }\end{array}$ & $\begin{array}{r}\text { (iii) Sand/ } \\
\text { macroalgae/ } \\
\text { corals }\end{array}$ & $\begin{array}{r}\text { (iv) Macroalgae/ } \\
\text { sand/ } \\
\text { turfs }\end{array}$ \\
\hline \multicolumn{6}{|c|}{ (A) Benthos (cover, \%) } \\
\hline & Corals & 60 & 15 & 10 & 0 \\
\hline & CCA & 20 & 5 & 5 & 0 \\
\hline & Halimeda & 0 & 10 & 5 & 5 \\
\hline & Algal turfs & 15 & 30 & 10 & 25 \\
\hline & Sand & 0 & 10 & 50 & 30 \\
\hline & Fleshy macroalgae & 5 & 30 & 20 & 40 \\
\hline \multicolumn{6}{|c|}{ (B) Impact on carbon chemistry $\left(\Delta \Omega_{\mathrm{a}} / \Delta t, \mathrm{~h}^{-1}\right)$ for whole communities at $1 \mathrm{~m}$ depth } \\
\hline \multirow[t]{6}{*}{ Low $\mathrm{CO}_{2}$} & Day & 0.21 & 0.40 & 0.28 & 0.47 \\
\hline & & $(0.08)$ & $(0.07)$ & $(0.05)$ & $(0.07)$ \\
\hline & Night & -0.43 & -0.32 & -0.20 & -0.22 \\
\hline & & $(0.09)$ & $(0.07)$ & $(0.05)$ & $(0.07)$ \\
\hline & Mean & -0.08 & 0.04 & 0.04 & 0.10 \\
\hline & & $(0.09)$ & $(\mathbf{0 . 1 0})$ & $(0.07)$ & $(0.07)$ \\
\hline \multirow[t]{6}{*}{ High $\mathrm{CO}_{2}$} & Day & 0.13 & 0.42 & 0.30 & 0.45 \\
\hline & & $(0.11)$ & $(0.06)$ & $(0.05)$ & $(0.06)$ \\
\hline & Night & -0.57 & -0.35 & -0.23 & -0.22 \\
\hline & & $(0.07)$ & $(0.07)$ & $(0.06)$ & $(0.08)$ \\
\hline & Mean & -0.23 & 0.04 & 0.04 & 0.12 \\
\hline & & $(0.12)$ & $(0.09)$ & $(0.07)$ & $(0.09)$ \\
\hline
\end{tabular}

\section{Discussion}

\subsection{Contributions from benthic groups to changes in reef water $\Omega_{\mathbf{a}}$}

The results of this study demonstrate that the carbon fluxes of six common benthic community groups drive seawater inorganic carbon-chemistry and carbonate saturation state changes in different directions and to varying extent in shallow-water reef habitats. At one extreme, reef-building corals (here represented by the branching species Acropora aspera) reduce the reef-water $\Omega_{\mathrm{a}}$ markedly, especially under ocean acidification (560-700 $\mu \mathrm{atm} \mathrm{CO}_{2}$ ). The net drawdown of $\Omega_{\mathrm{a}}$ by corals is partly due to high rates of day- and nighttime calcification and respiration. Specifically, changes in $\Omega_{\mathrm{a}}$ driven by corals stems from the coupling and ratio of net organic carbon production to net calcification, and the subsequent modification on the seawater $C_{\mathrm{T}}: A_{\mathrm{T}}$ ratio (Suzuki and Kawahata, 2003; Andersson and Gledhill, 2013). At typical coral reef seawater conditions, and assuming constant temperature and salinity, a $\Delta C_{\mathrm{T}}: \Delta A_{\mathrm{T}}$ ratio approximately equal to 1 results in no net change in the seawater $\Omega_{\mathrm{a}}$, while changes at a ratio $>1$ will increase $\Omega_{\mathrm{a}}$, and changes at a ratio $<1$ will reduce $\Omega_{\mathrm{a}}$ (Andersson and Gledhill, 2013). In the present case, net coral calcification was only negatively affected at high $\mathrm{CO}_{2}$ and low flow, whereas net coral production strongly decreased during the day and respiration strongly increased at night under all high $\mathrm{CO}_{2}$ conditions. The increased metabolic activity may indicate that the corals were stressed or simply had to work harder to maintain their calcification rates under these conditions. At the other extreme, macroalgae, turfs and sand communities contributed on average with positive changes in $\Omega_{\mathrm{a}}$ of the reef water. This was illustrated most clearly by the coral-degraded back reef scenario (Table 1iv). Here, the average day and nighttime changes in $\Omega_{\mathrm{a}}$ approximated around $0.12 \pm 0.09 \mathrm{~h}^{-1}$ at both low $\mathrm{CO}_{2}(350-450 \mu \mathrm{atm})$ and under acidified conditions. This result implies that extensive areas dominated by macroalgae, turfs and sand may partially counteract net reductions in $\Omega_{\mathrm{a}}$ by corals and CCA, depending partly on the residence time of water over each habitat type and partly on their upstream-downstream arrangement. The projections of 
$\Omega_{\mathrm{a}}$ changes for water over mixed reef communities (ii and iii) supported this hypothesis as their average net $\Omega_{\mathrm{a}}$ changes were intermediate of those of the coral dominated (i) and macroalgal/sand turf dominated (iv) communities.

Benthic carbon fluxes and their contributions to changes in $\Omega_{\mathrm{a}}$ showed mixed responses to $\mathrm{CO}_{2}$ and flow variation across the benthic groups. Interestingly, high flow speed ( 35 compared to $8 \mathrm{~cm} \mathrm{~s}^{-1}$ ) did not enhance calcification in corals, CCA or Halimeda under ambient $\mathrm{CO}_{2}$. Under acidification, however, high water flow increased calcification to the extent that it effectively counteracted the observed negative effect of acidification at low flow. Flow has previously been demonstrated to enhance coral calcification (Dennison and Barnes, 1988), photosynthesis (Mass et al., 2010) and respiration (Patterson et al., 1991) through forced convection (Patterson, 1992) and increased time-integrated supply of food and nutrients. Furthermore, as effects of flow increments on mass transfer are strongest for flows below around $5 \mathrm{~cm} \mathrm{~s}^{-1}$ (Baird and Atkinson, 1997) it is likely that the mass fluxes of carbon species affecting rate-limitation of calcification in this study were already strongly elevated at $8 \mathrm{~cm} \mathrm{~s}^{-1}$. Nonetheless, the positive interaction between flow and acidification on coral net calcification may be attributed to the increased supply of food and nutrients, but further investigation is required to fully explore these results.

Acidification reduced calcification of CCA but only at low flow (Fig. 5b). The mechanism by which increased water flow ameliorated the effects of ocean acidification on CCA is not clear, but could partly be due to increased supply of nutrients. However, as production and calcification are positively correlated, and since we found enhanced production of CCA with increasing water flow (Fig. 5b), possibly due to increased supply of $\mathrm{CO}_{2}$ to the site of photosynthesis (particularly under acidification), it is likely that production enhanced calcification in our experiments. These results partly support the observation that CCAs typically thrive in highenergy environments (Chisholm, 2003). In contrast, calcification by turfs, and to a larger extent the sand community, responded negatively to both acidification and flow, as the rate of net dissolution by sand was exacerbated under high flow. These results are consistent with observations from field studies of calcification/dissolution responses of sand and sediment communities on Heron reef under natural carbon chemistry variation and tidal cycles (Santos et al., 2011).

The strong interaction between flow and acidification in their impact on net photosynthesis of turfs and macroalgae may be explained by two processes: First, since $\mathrm{CO}_{2}$ is a substrate for algal photosynthesis (Lobban and Harrison, 1997) an increase in $\mathrm{CO}_{2}$ can potentially enhance algal photosynthesis (at least for those species relying on $\mathrm{CO}_{2}$ utilisation via diffusion, e.g. red algal turfs, Fig. 5b) (Raven, 2011). Second, increased flow means breakdown of boundary layers over the thick algal mats and mixing of water in between the thalli, contributing to nutrient uptake, including uptake of carbon (Wheeler, 1980) and enhanced gas exchange. For example, net primary productivity of tropical algal turfs and seaweeds was significantly enhanced by increased water flow in the Caribbean (Carpenter et al., 1991). Similar processes may be occurring during dark respiration. Under ambient, nonacidification scenarios, the response of turf algae and fleshy macroalgae to increased flow was minor, compared to a dramatic increase in both net production and respiration under high flow and acidification treatments, supporting the importance of water flow as a major driver of carbon fluxes particularly in reefs dominated by algae.

Patterns of $\Delta \Omega_{\mathrm{a}} / \Delta t$ were driven by flux contributions from calcification and respiration (negative $\Delta \Omega_{\mathrm{a}}$ contributions via a relative increase in the $C_{\mathrm{T}}: A_{\mathrm{T}}$ ratio, Fig. 1), and from photosynthesis and dissolution (positive $\Delta \Omega_{\mathrm{a}}$ contributions by a relative decrease in the $C_{\mathrm{T}}: A_{\mathrm{T}}$ ratio). For all groups, variation in net production was more diagnostic of $\Omega_{\mathrm{a}}$ variation than was net calcification. For example, the effect of acidification on the contribution of corals to changes in $\Omega_{\mathrm{a}}$ were driven mostly by the $20-40 \%$ decrease in net photosynthesis and 30-50\% increase in dark respiration (Figs. 5 and 6). Also, the pattern of variation in $\Omega_{\mathrm{a}}$ of the flume water over Halimeda was mapped more by the pattern of net photosynthesis than by that of calcification. Importantly, $\Delta \Omega_{\mathrm{a}} / \Delta t$ was here normalised to a $1 \mathrm{~m}$ deep water column, but is scalable to other depths depending on the degree of vertical mixing.

The ratio of $C_{\mathrm{T}}: A_{\mathrm{T}}$ ratio is partly influenced by the ratio of photosynthesis to respiration ( $\mathrm{P}: \mathrm{R}$ ratio). Several studies have suggested that the $\mathrm{P}: \mathrm{R}$ ratio on coral reefs converge on unity, partly due to high autotrophic respiration under nutrient limited conditions (e.g. Falter et al., 2011). However, our results do not directly support this hypothesis for two reasons. Firstly, the ratio of daytime to nighttime rates of NCP for the six benthic groups varied to different degrees across flow and $\mathrm{CO}_{2}$ treatments (Fig. 5). Secondly, our study only includes some, albeit dominant, components of the reef benthos, and does not capture the contribution from other key groups such as filter feeders and the plankton community.

\subsection{How does benthic community composition affect seawater chemistry?}

Our analyses showed that variations in benthic compositions, especially for corals and macroalgae, can lead to large spatial and diurnal variations in $\Omega_{\mathrm{a}}$ in shallow water. In extensive back-reef and lagoonal environments on reefs like Heron Reef (10 km scale), even small variations in net community calcification and production by sand and the turf assemblages, which both contribute relatively little to $\Omega_{\mathrm{a}}$ changes per unit time and per $\mathrm{m}^{2}$, may translate to large absolute contributions to $\Omega_{\mathrm{a}}$ changes in downstream habitats. Transitions from coral-CCA dominance to algal and turf dominance on reef systems subjected to disturbances (e.g. Done, 1992) may hence shift the seawater carbonate chemistry dramatically. For example, the net balance in $\Omega_{\mathrm{a}}$ in a system with abundant 
calcifying groups is negative, while the opposite occurs in reefs with dominance of benthic seaweeds, algal turfs and sand. These findings have important implications for understanding variability in carbon fluxes and calcification in the GBR and suggest that degraded coral reefs may contribute positively to calcification in downstream habitats.

Potential positive effects of macroalgae on reef acidification (e.g. by providing "chemical resilience" to the system) may be counteracted by negative effects of macroalgae on ecological resilience, e.g. coral recruitment and space competition (McCook et al., 2001; Diaz-Pulido et al., 2010). This negative effect will, however, depend on the type of macroalgae dominating the reef. For example, reefs dominated by seaweeds that are known to kill corals through secondary metabolites, such as Lobophora, Chlorodesmis (Rasher and Hay, 2010; Diaz-Pulido et al., 2011), or by altering microbial environments on the surface of the corals (Smith et al., 2006) may not benefit from seaweed abundance. On the other hand, reefs with abundant seaweeds that are not chemically loaded such as Chnoospora, Hydroclathrus, etc, may benefit substantially by algal abundance, disregarding other indirect affects arising from for example competition for space and nutrients. Reefs adjacent to seagrass beds and back-reef areas with abundant brown algal populations can also potentially benefit from these scenarios (Anthony et al., 2011; Mcleod et al., 2013).

Acknowledgements. We thank staff at Heron Island Research Station for logistical support and K. Berry for help with analyses of seawater carbon chemistry. Two anonymous reviewers provided constructive comments that improved the manuscript. This study was funded by a Linkage Grant from the Australian Research Council and the Great Barrier Reef Marine Park Authority to K. R. N. Anthony and G. Diaz-Pulido, and by the Great Barrier Reef Foundation. A. J. Andersson acknowledges support from NSF OCE-0928406.

Edited by: U. Riebesell

\section{References}

Andersson, A. J. and Gledhill, D.: Ocean acidification and coral reefs: Effects on breakdown, dissolution and net ecosystem calcification, Annu. Rev. Mar. Sci., 5, 321-348, doi:10.1146/annurevmarine-121211-172241, 2013.

Andersson, A. J., Kuffner, I. B., Mackenzie, F. T., Jokiel, P. L., Rodgers, K. S., and Tan, A.: Net Loss of $\mathrm{CaCO}_{3}$ from a subtropical calcifying community due to seawater acidification: mesocosm-scale experimental evidence, Biogeosciences, 6 , 1811-1823, doi:10.5194/bg-6-1811-2009, 2009.

Anthony, K. R. N., Kline, D. I., Diaz-Pulido, G., Dove, S., and Hoegh-Guldberg, O.: Ocean acidification causes bleaching and productivity loss in coral reef builders, P. Natl. Acad. Sci., 105, 17442-17446, 2008.

Anthony, K. R. N., Kleypas, J., and Gattuso, J.-P.: Coral reefs modify the carbon chemistry of their seawater - implications for the impacts of ocean acidification, Glob. Change Biol., 17, 36553666, 2011.

Baird, M. E. and Atkinson, M. J.: Measurement and prediction of mass transfer to experimental coral reef communities, Limnol. Oceanogr., 42, 1685-1693, 1997.

Bates, N. R. and Peters, A. J.: The contribution of atmospheric acid deposition to ocean acidification in the subtropical North Atlantic Ocean, Mar. Chem., 107, 547-558, 2007.

Bates, N. R., Amat, A., and Andersson, A. J.: Feedbacks and responses of coral calcification on the Bermuda reef system to seasonal changes in biological processes and ocean acidification, Biogeosciences, 7, 2509-2530, doi:10.5194/bg-7-25092010, 2010.

Caldeira, K. and Wickett, M. E.: Anthropogenic carbon and ocean pH, Nature, 425, 365, doi:10.1038/425365a, 2003.

Carpenter, R. C., Hackney, J. M., and Adey, W. H.: Measurements of primary productivity and nitrogenase activity of coral reef algae in a chamber incorporating oscillatory flow, Limnol. Oceanogr., 36, 40-49, 1991.

Chisholm, J. R. M.: Calcification by crustose coralline algae on the northern Great Barrier Reef, Australia, Limnol. Oceanogr., 45, 1476-1484, 2000.

Chisholm, J. R. M.: Primary productivity of reef-building crustose coralline algae, Limnol. Oceanogr., 48, 1376-1387, 2003.

Dennison, W. C. and Barnes, D. J.: Effects of water motion on coral photosynthesis and calcification, J. Exp. Mar. Biol. Ecol., 115, 67-77, 1988.

Diaz-Pulido, G., Harii, S., McCook, L. J., and Hoegh-Guldberg, O.: The impact of benthic algae on the settlement of a reef-building coral, Coral Reefs, 29, 203-208, 2010.

Diaz-Pulido, G., Gouezo, M., Tilbrook, B., Dove, S. G., and Anthony, K. R. N.: High $\mathrm{CO}_{2}$ enhances the competitive strength of seaweeds over corals, Ecol. Lett., 14, 156-162, 2011.

Dickson, A. G., Afghan, J. D., and Anderson, G. C.: Reference materials for oceanic $\mathrm{CO}_{2}$ analysis: a method for the certification of total alkalinity, Mar. Chem., 80, 185-197, 2003.

Dickson, A. G., Sabine, C. L., and Christian, J. R.: Guide to best practices for ocean $\mathrm{CO}_{2}$ measurements, PICES special publication 3, IOCCP report No. 8, 2007.

Done, T. J.: Phase shifts in coral reef communities and their ecological significance, Hydrobiologia, 247, 121-132, 1992.

Duarte, C., Hendriks, I., Moore, T., Olsen, Y., Steckbauer, A., Ramajo, L., Carstensen, J., Trotter, J., and Mcculloch, M.: Is Ocean Acidification an Open-Ocean Syndrome? Understanding Anthropogenic Impacts on Seawater pH, Estuar. Coasts, 36, 221236, 2013.

Falter, J. L., Lowe, R. J., Atkinson, M. J., Monismith, S. G., and Schar, D. W.: Continuous measurements of net production over a shallow reef community using a modified Eulerian approach, J. Geophys. Res., 113, C07035, doi:10.1029/2007JC004663, 2008.

Falter, J. L., Atkinson, M. J., Schar, D. W., Lowe, R. J., and Monismith, S. G.: Short-term coherency between gross primary production and community respiration in an algal-dominated reef flat, Coral Reefs, 30, 53-58, 2011.

Gattuso, J.-P., Pichon, M., and Frankignoulle, M.: Biological control of air-sea $\mathrm{CO}_{2}$ fluxes: effect of photosynthetic and calcifying marine organisms and ecosystems, Mar. Ecol.-Prog. Ser., 129, 307-312, 1995. 
Gledhill, D. K., Wanninkhof, R., Millero, F. J., and Eakin, C. M.: Ocean acidification of the Greater Caribbean Region 1996-2006, J. Geophys. Res., 113, C10031, doi:10.1029/2007JC004629, 2008.

Gourlay, M. R. and Colleter, G.: Wave-generated flow on coral reefs - an analysis for two-dimensional horizontal reef-tops with steep faces, Coast. Eng., 52, 353-387, 2005.

Hoegh-Guldberg, O., Mumby, P. J., Hooten, A. J., Steneck, R. S., Greenfield, P., Gomez, E., Harvell, C. D., Sale, P. F., Edwards, A. J., Caldeira, K., Knowlton, N., Eakin, C. M., Iglesias-Prieto, R., Muthiga, N., Bradbury, R. H., Dubi, A., and Hatziolos, M. E.: Coral reefs under rapid climate change and ocean acidification, Science, 318, 1737-1742, 2007.

Johnson, K. M., Wills, K. D., Butler, D. B., Johnson, W. K., and Wong, C. S.: Coulometric total carbon dioxide analysis for marine studies: maximizing the performance of an automated continuous gas extraction system and coulometric detector, Mar. Chem., 44, 167-187, 1993.

Kleypas, J. A., Buddemeier, R. W., Archer, D., Gattuso, J. P., Langdon, C., and Opdyke, B. N.: Geochemical consequences of increased atmospheric carbon dioxide on coral reefs, Science, 284, 118-120, 1999.

Kleypas, J., Gattuso, J.-P., and Anthony, K. R. N.: Coral reefs modify their seawater carbon chemistry - case study from a barrier reef (Moorea, French Polynesia), Glob. Change Biol., 17, 36673678, 2011.

Kroeker, K., Kordas, R. L., Crim, R. N., and Singh, G. G.: Metaanalysis reveals negative yet variable effects of ocean acidification on marine organisms, Ecol. Lett., 13, 1419-1434, 2010.

Langdon, C. and Atkinson, M. J.: Effect of elevated $p \mathrm{CO}_{2}$ on photosynthesis and calcification of corals and interactions with seasonal change in temperature/irradiance and nutrient enrichment, J. Geophys. Res.-Oceans, 110, C09S07, doi:10.1029/2004JC002576, 2005.

Lewis, E. and Wallace, D. W. R.: Program developed for $\mathrm{CO}_{2}$ system calculations, ORNL/CDIAC-105, Carbon Dioxide Information Analysis Center, Oak Ridge National Laboratory, US Department of Energy, Oak Ridge, Tennessee, 1998.

Lobban, C. S. and Harrison, P. J.: Seaweed ecology and physiology, Cambridge University Press, 1997.

Mass, T., Genin, A., Shavit, U., Grinstein, M., and Tchernov, D.: Flow enhances photosynthesis in marine benthic autotrophs by increasing the efflux of oxygen from the organism to the water, P. Natl. Acad. Sci., 107, 2527-2531, 2010.

McCook, L. J., Jompa, J., and Diaz-Pulido, G.: Competition between corals and algae on coral reefs: a review of evidence and mechanisms, Coral Reefs, 19, 400-417, 2001.

Mcleod, E., Anthony, K. R. N., Andersson, A. J., Beeden, R., Golbuu, Y., Kleypas, J., Kroeker, K., Manzello, D., Salm, R. V., Schuttenberg, H., and Smith, J. E.: Preparing to manage coral reefs for ocean acidification: lessons from coral bleaching, Front. Ecol. Environ., 11, 20-27, doi:10.1890/110240, 2013.

Orr, J.: Recent and future changes in carbonate chemistry, in: Ocean Acidification, edited by: Gattuso, J.-P. and Hansson, L., Oxford University Press, 2011.

Patterson, M. R.: A mass transfer explanation of metabolic scaling relations in some aquatic invertebrates and algae, Science, 255, 1421-1423, 1992.
Patterson, M. R., Sebens, K. P., and Olson, R. R.: In situ measurements of flow effects on primary production and dark respiration in reef corals, Limnol. Oceanogr., 35, 936-948, 1991.

Phinn, S., Roelfsema, C., and Mumby, P. J.: Multi-scale, objectbased image analysis for mapping geomorphic and ecological zones on coral reefs, Int. J. Remote Sens., 33, 3768-3797, 2012.

Rasher, D. B. and Hay, M. E.: Chemically rich seaweeds poison corals when not controlled by herbivores, P. Natl. Acad. Sci. USA, 107, 9683-9688, 2010.

Raven, J. A.: Effects on marine algae of changed seawater chemistry with increasing atmospheric $\mathrm{CO}_{2}$, Biol. Environ., 111B, 1-17, 2011.

Raven, J. A., Caldeira, K., Elderfield, H., Hoegh-Guldberg, O., Liss, P., Riebesell, U., Shepherd, J., Turley, C., and Watson, A.: Ocean acidification due to increasing atmospheric carbon dioxide, The Royal Society, 2005.

Robbins, L. L., Hansen, M. E., Kleypas, J. A., and Meylan, S. C.: $\mathrm{CO}_{2}$ calc - A user-friendly seawater carbon calculator for Windows, Max OS X, and iOS (iPhone) p. 17, US Geological Survey Open-File Report 2010-1280, 2010.

Sabine, C. L., Sabine, C. L., Feely, R. A., Gruber, N., Key, R. M., Lee, K., Bullister, J. L., Wanninkhof, R., Wong, C. S., Wallace, D. W. R., Tilbrook, B., Millero, F. J., Peng, T.-H., Kozyr, A., Ono, T., and Rios, A. F.: The oceanic sink for anthropogenic $\mathrm{CO}_{2}$, Science, 305, 367-371, 2004.

Santos, I. R., Glud, R. N., Maher, D., Erler, D., and Eyre, B. D.: Diel coral reef acidification driven by porewater advection in permeable carbonate sands, Heron Island, Great Barrier Reef, Geophys. Res. Lett., 38, L03604, doi:10.1029/2010GL046053, 2011.

Schneider, K. and Erez, J.: The effect of carbonate chemistry on calcification and photosynthesis in the hermatypic coral Acropora eurystoma, Limnol. Oceanogr., 51, 1284-1293, 2006.

Silverman, J., Lazar, B., and Erez, J.: Effect of aragonite saturation, temperature, and nutrients on the community calcification rate of a coral reef, J. Geophys. Res.-Oceans, 112, C05004, doi:10.1029/2006JC003770, 2007.

Silverman, J., Lazar, B., Cao, L., Caldeira, K., and Erez, J.: Coral reefs may start dissolving when atmospheric $\mathrm{CO}_{2}$ doubles, Geophys. Res. Lett., 36, L05606, doi:10.1029/2008GL036282, 2009.

Smith, J. E., Shaw, M., Edwards, R. A., Obura, D., Pantos, O., Sala, E., Sandin, S. A., Smriga, S., Hatay, M., and Rohwer, F. L.: Indirect effects of algae on coral: algae-mediated, microbe-induced coral mortality, Ecol. Lett., 9, 835-845, 2006.

Suzuki, A. and Kawahata, H.: Carbon budget of coral reef systems: an overview of observations in fringing reefs, barrier reefs and atolls in the Indo-Pacific regions, Tellus B, 55, 428-444, 2003.

Suzuki, A., Nakamori, T., and Kayanne, H.: The mechanism of production enhancement in coral reef carbonate systems: Model and empirical results, Sediment. Geol., 99, 259-280, 1995.

Wanninkhof, R.: Relationship between wind speed and gas exchange over the ocean, J. Geophys. Res., 97, 7373-7382, 1992.

Wheeler, W. N.: Effect of boundary-layer transport on the fixation of carbon by the giant-kelp Macrocystis pyrifera, Mar. Biol., 56, 103-110, 1980.

Zeebe, R. E. and Wolf-Gladrow, D.: $\mathrm{CO}_{2}$ in seawater: equilibrium, kinetics, isotopes, Elsevier, 2001. 